\title{
Comparison of Helium and Argon as Collision Gases in the High Energy Collision-Induced Decomposition of $\mathrm{MH}^{+}$Ions of Peptides
}

\author{
Jozsef Bordas-Nagy, Dominique Despeyroux, and Keith R. Jennings \\ Department of Chemistry, University of Warwick, Coventry, England
}

\begin{abstract}
Collision-induced decompositions (CID) of protonated peptides were studied using a four-sector mass spectrometer. The collision gases employed were helium and argon. The CID spectra of several peptides covering the molecular mass region of 905-2465 a were recorded. These investigations established several previously unrecognized differences between the CID spectra obtained with helium and argon as collision gases. These can be summarized as follows: (1) Structurally significant and specific side chain fragmentations $\left(\mathrm{d}_{n}, \mathrm{w}_{n}\right.$, and $\mathrm{v}_{n}$ ion types) are greatly reduced or completely missing in the CID spectra obtained with helium as a collision gas compared to those obtained with argon. (2) As the peptide molecular mass increases, argon, which is heavier than helium, is increasingly more efficient than helium for generating fragment ions. (f Am Soc Mass Spectrom 1992, 3, 502-514)
\end{abstract}

$\mathrm{T}$ The introduction of soft ionization techniques such as fast atom bombardment (FAB) [1] and liquid secondary ion mass spectrometry (LSIMS) [2], in each of which a liquid matrix is used, has provided a means of generating intense ion beams from thermally labile molecules such as peptides, thereby allowing them to be studied by means of mass spectrometry. Neither ionization method readily gives structural information on peptides, however, primarily because the protonated molecules, $\mathrm{MH}^{+}$, generated by these techniques do not fragment extensively and there is strong interference ("chemical noise") from ions generated from the liquid matrix.

Tandem mass spectrometry [3], or mass spectrometry/mass spectrometry (MS/MS), has been successfully used to overcome these problems. This technique employs two mass spectrometers (or analyzers) in tandem, the first (MS-I) being used to select ions of a particular mass. These ions are focused so as to pass into a collision cell placed between MS-I and MS-II in which collisions take place between the ions and a collision gas, such as helium or argon, which is introduced into the cell. Among other processes, collision-induced decomposition (CID) of the primary ion beam will occur, generating a number of fragment ions of mass-to-charge ratio $(\mathrm{m} / \mathrm{z})$ characteristic of the structure of the primary ion. These fragment ions are

Address reprint requests to Keith R. Jennings, Department of Chemistry, University of Warwick, Coventry CV4 7AL, England, UK. analyzed by means of the second mass spectrometer, MS-II.

If the tandem mass spectrometer is a triplequadrupole $[4,5]$ or a hybrid instrument $[6,7]$, low energy ( $E_{\mathrm{kin}} \leq 100 \mathrm{eV}$ ) CID occurs. The use of low energy CID for peptide sequencing has been thoroughly described recently [8-11]. Low energy CID produces abundant fragment ions from $\mathrm{MH}^{+}$ions of smaller peptides (relative molecular mass up to about 800); high energy CID gives more complete sequence information for higher mass peptides [11]. High energy CID ( $E_{\mathrm{kin}} \geq 1 \mathrm{keV}$ ) experiments are carried out in sector instruments, and early work on two-sector instruments made use of mass-analyzed ion kinetic energy spectroscopy (MIKES) [12] or a linked scan in which the ratio of magnetic and electric sector field strengths $(B / E)$ was kept constant [13]. Neither of these techniques offers good mass resolution of both primary and secondary ions.

Tandem double-focusing mass spectrometers [14-20] currently provide one of the best methods for the sequencing of peptides. The combination of high resolving power of MS-I and MS-II, the accuracy of fragment ion mass assignment $( \pm 0.2 \mathbf{u})$, and the high energy CID conditions allow the sequencing of peptides containing up to 25 amino acid residues [18]. Although these instruments have now been in use for several years, there has to our knowledge been no report in the literature of a systematic study of the effects of varying the nature and pressure of the 
collision gas, although brief accounts of such studies have appeared in conference proceedings $[16,19]$. Carr et al. [16] reported that when argon was used as the collision gas, the fragment ion spectra obtained from a VG ZAB-SE $4 \mathrm{~F}$ four-sector instrument contained peaks due to fragment ions that were not present when helium was used as the collision gas. The differences were mainly in the heights of peaks arising from ions that require multiple bond cleavages for their formation. For peptides of relative molecular mass (RMM) above 2000, however, argon could not be used because ion losses, presumably due to scattering, outweighed the advantages of using the heavier collision gas. Curtis et al. [19], using a VG 70-4SE four-sector instrument, investigated the efficiency of fragment ion production in the CID of peptides as a function of the peptide RMM and the type of collision gas used. From the results of studies of a model peptide (physalaemin, RMM 1264.6), they concluded that for ions of $m / z 500-1500$, light collision gases such as helium and hydrogen give a greater relative yield of high mass ions, whereas heavier collision gases such as nitrogen, argon, and xenon give a greater relative yield of low mass ions. As a compromise for this mass region, they suggested the use of a mixture of light and heavy collision gases to optimize the fragmentation. For peptides of RMM greater than 1500 , the light collision gases became very much less efficient than the heavy gases in promoting fragmentation.

The major classes of fragment ions formed in the high energy $\mathrm{CID}$ of $\mathrm{MH}^{+}$ions of peptides have been described previously. In Scheme I, the types of fragment ion arising from cleavage along the polyamide backbone of a peptide are illustrated. These types of fragment ion ( $a, b, c, x, y$, and $z$ ions) were first observed in the FAB/MS spectra of peptides [23-25] and subsequently in their high energy $\mathrm{CID}$ spectra [26]. Additional fragment ions, the formation of which requires a backbone cleavage and the loss of the whole or part of the side chain of an amino acid, have been observed by Biemann and co-workers $[27,28]$. The structure and mechanism of formation of these ions $\left(d_{n}, w_{n}\right.$, and $\left.v_{n}\right)$ are illustrated in Scheme II. Because the formation of these ions requires the breaking of more than one bond, their formation is expected to require significantly higher internal energies than those leading to the ions formed by back-

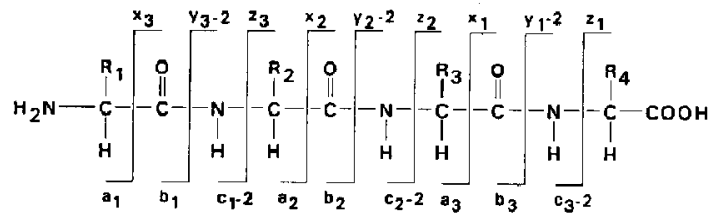

Scheme I. Fragments produced from protonated linear peptides $[21,22]$.
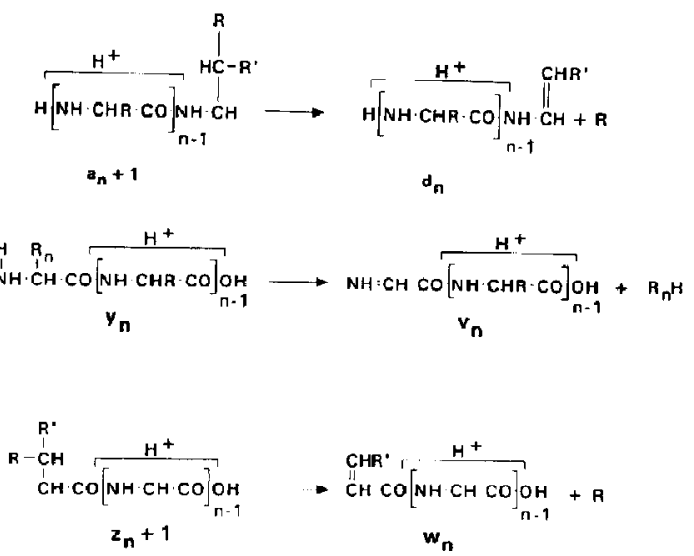

Scheme II. Mechanisms leading to $\mathrm{d}_{m}, \mathrm{v}_{n}$, and $\mathrm{w}_{n}$ ions.

bone cleavage alone. This suggestion is supported by the results of Martin and Biemann and associates [29, 30] concerning the kinetic energy dependence of the relative abundances of backbone and side chain fragments. When helium was used as the collision gas, the relative abundance of the side chain fragments decreased rapidly at primary ion energies of less than $2000 \mathrm{eV}$, but when xenon was the collision gas, this effect was observed only below primary ion energies of $400 \mathrm{eV}$.

Biemann and co-workers have alsu shuwn that the fragmentation behavior of $\mathrm{MH}^{+}$ions of peptides undergoing high energy CID can be classified in terms of the extent of the localization of charge along the peptide chain [28,31,32]. They found two limiting cases: (1) Almost complete delocalization of charge in $\mathrm{MH}^{+}$ions of peptides containing no basic amino acids. The delocalization is complete if the peptide is $\mathrm{N}$-acylated. The CID spectra of these ions consist mainly of $b_{n}$ ions and some $y_{n}$ ions. (2) Almost complete localization of charge in $\mathrm{MH}^{+}$ions of peptides containing an arginine residue, the localization being complete if there is a quaternary ammonium group in the peptide. If the charge is localized at or near the $\mathrm{N}$-terminal end of the ion, the CID spectrum contains mainly $\mathrm{a}_{n}$ and $\mathrm{d}_{n}$ ions, whereas if it is localized at the C-terminal end, mainly $\mathrm{y}_{n}, \mathrm{v}_{n}$, and $\mathrm{w}_{n}$ ions are present in the spectrum.

Peptides that contain amino acids that are less basic than arginine, such as histidine and lysine, exhibit behavior between these two limiting cases. The above observations are discussed in more detail elsewhere [28].

Notwithstanding the collision gas effects described above, most reports of work carried out on four-sector tandem mass spectrometers concerning the CID of peptides or other large biomolecules indicate that helium is used as the collision gas. We therefore carried out a detailed study of the nature of the collision gas on the CID spectra of peptides. These studies were 
carried out on peptides having a RMM of 905-2465 and taking into consideration the very different fragmentation behavior of the various classes of peptide described above, three classes of peptide were studied:

1. Peptides containing arginine at the $\mathrm{N}$-terminal end

2. Peptides containing arginine at the C-terminal end

3. Peptides containing no basic amino acid

These studies revealed marked differences in the CID spectra that have not been reported previousiy.

\section{Experimental}

All experiments were carried out using a Kratos "Concept" II HH four-sector tandem mass spectrometer (Kratos Analytical, Ramsey, NJ). This instrument has been described in detail elsewhere, and we describe only experimental conditions of importance in the present work. Ions were generated by FAB, using xenon atoms of $8 \mathrm{keV}$ translational energy. All peptides were obtained from Sigma Chemical Corporation (St. Louis, MO) and were used without further purification. Samples were dissolved in a 1:1 mixture of glycerol and monothioglycerol to give a solution of 2-5 nmol $/ \mu \mathrm{L}$ of which $1 \mu \mathrm{L}$ was placed on the probe tip. To this solution a trace of trifluoroacetic acid (TFA) was added to promote the production of protonated peptides in the FAB ionization process. For peptides containing one or more disulfide bridges, the FAB conditions were as described elsewhere [20] so as to reduce fully the disulfide bridges. It should be cmphasized that very acceptable spectra could be obtained with much smaller samples, but the primary aim of the present work was to demonstrate the differences in relative abundances of certain fragment ions rather than to determine the overall sensitivity of the experiment.

MS-I was operated with an accelerating voltage of $8 \mathrm{kV}$, and the resolution was adjusted so as to achieve baseline separation of the ${ }^{12} \mathrm{C}$ peak in the isotope cluster of the $\mathrm{MH}^{+}$ion. The ions giving this ${ }^{12} \mathrm{C}$ peak were selected by MS-I and focused into the collision cell, which was floated at a potential of $4 \mathrm{kV}$ above earth potential. Collision gases were obtained from Matheson (East Rutherford, NJ) and were of researchgrade purity, and after a detailed study of the effects of various collision gas pressures, the collision gas pressure in the collision cell was adjusted to attenuate the primary ion beam by $70 \%$ for helium and $75 \%$ for argon.

The collision gas inlet system was designed so that switching between collision gases could be accomplished without disassembling any part of the system. The collision gas inlet line could be evacuated to a pressure of $10^{-2}$ torr, and when switching from one collision gas to another, the line was flushed out with the new gas and evacuated several times. Care in ensuring the purity of the collision gas was found to be crucial because traces of a heavier collision gas, including air, had a very strong effect on the CID spectra obtained when helium was used as the collision gas.

All CID spectra were obtained by means of a linked scan of the electric and magnetic sector field strengths, E2 and B2, of MS-II under control of the DS90 data system. A scan speed of $30 \mathrm{~s} /$ decade was used with $100 \mathrm{~Hz}$ filtering. The profile data collected were averaged, and the centroids of the peaks in the resulting spectrum were used for mass assignment by the DS90 data system. The second mass spectrometer, MS-II, was calibrated by means of a Phrasor FAB probe inserted into the collision chamber through a vacuum lock; this gave an accuracy of mass assignment of better than $\pm 0.3 \mathrm{u}$. Experimental conditions were carefully chosen so that the intensity of the primary ion beam did not change by more than $\pm 20 \%$ between successive scans; this was achieved by applying relatively large samples $(2-5 \mathrm{nmol})$ to the probe tip and cooling the probe. For these experiments the multiplier gain was set such that the signal due to the primary ion was saturated. Consequently, in the spectra obtained with the data system, although the relative heights of the fragment ion peaks are correct, they do not reflect their true levels relative to the primary ion peak. To be able to assess the effect of the nature of the collision gas on the efficiency of fragment ion production in the CID experiments, the true heights of several intense fragment ion peaks were measured relative to the precursor ion peak in a separate experiment for each spectrum recorded. These measurements were used to obtain the multiplication factors shown in each spectrum.

To try to ensure uniform operating conditions throughout this set of experiments, the instrument was tuned at the beginning of each working day to produce the optimum CID spectrum of the $\mathrm{m} / \mathrm{z} 1692$ ion of cesium iodide produced by FAB ionization. The optimum conditions were identified with the establishing of maximum transmission of the primary ion and all fragment ions simultaneously.

\section{Results and Discussion}

\section{Peptides Containing Arginine at the N-Terminal End}

In Figure 1, CID spectra of substance $P$ are shown as observed using helium and argon as target gases. The spectrum obtained using helium as the target gas has similar characteristics to spectra cited in the literature that have often been used as a test for the performance of tandem instruments $[32,33]$. It contains an almost complete series of $a_{n}$ ions and $d_{n}$ ions in 
significant abundance except for the proline (positions 2 and 4), glycine (position 9), and phenylalanine (positions 7 and 8 ) residues. The proline and glycine residues cannot give rise to any $\mathrm{d}_{n}$ fragments by definition (see Scheme II). Johnson et al. [28], who used helium exclusively as the target gas, noted in their original paper on the formation of $d_{n}$ ions that amino acids with aromatic side chains give rise to very low abundances of such ions. The spectrum obtained using argon as the target gas significantly enhances the peaks due to $d_{n}$ ions relative to those of $\mathrm{a}_{n}$ ions, as previously noted by Carr et al. [16]. Fur-

Substance P $\mathrm{MH}^{+}$: 1347.7

(a) Arg-Pro-Lys-Pro-GIn-GIn-Phe-Phe-Gly-Leu-Met-NH2

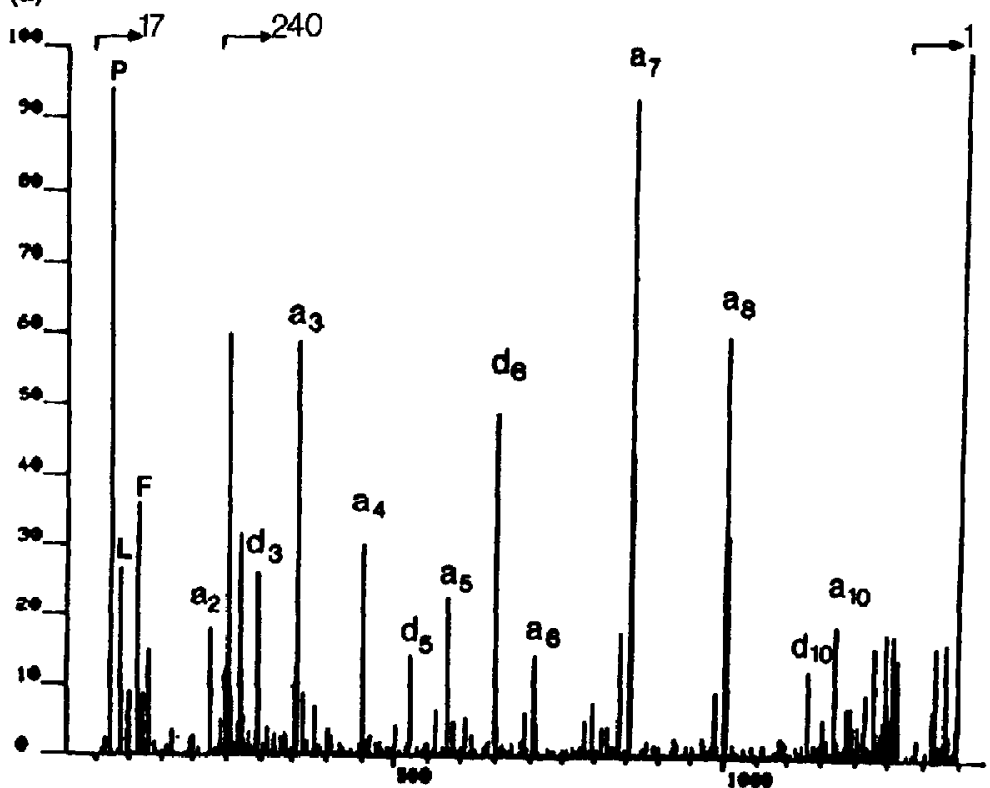

(b)

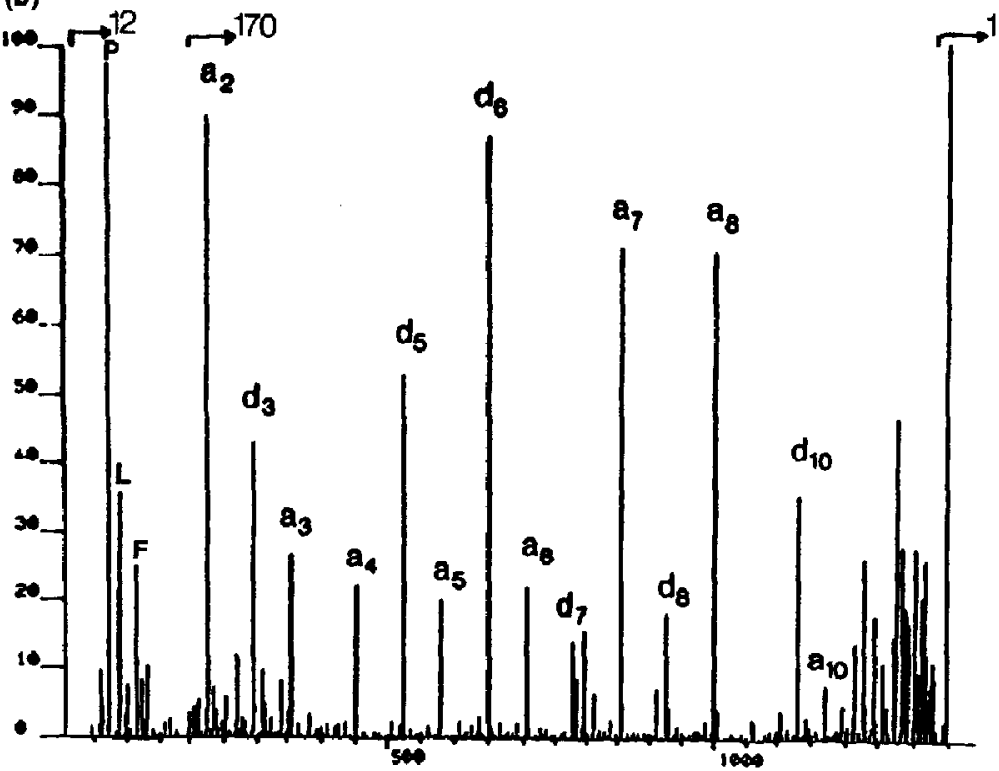

Figure 1. The CID spectrum of the $\mathrm{MH}^{+}$Ion of Substance $\mathrm{P}(\mathrm{m} / \mathrm{z}$ 1347.7) obtained using (a) helium and (b) argon as the collision gas and a collision cell potential of $4 \mathrm{kV}$. 
thermore, there are $\mathrm{d}_{n}$ ions of significant abundance arising from the phenylalanine residues $\left(d_{7}\right.$ and $\left.d_{8}\right)$, which are essentially absent from the spectrum obtained using helium as the target gas. These observations indicate that high energy collisions of the $\mathrm{MH}^{+}$ ion of substance $P$ with argon deposit more internal energy into the ion than similar collisions with helium [34]. Further support for this conclusion can be obtained from the data shown in Table 1. This table lists the heights, as a percentage of the intensity of the $\mathrm{MH}^{+}$ion peak, of the peaks arising from the $\mathrm{a}_{H}+1$, $\mathrm{a}_{n}$, and $\mathrm{d}_{n}$ ions formed from the phenylalanine residues of substance $P$ when helium and argon were used as collision gases. On excitation, $a_{n}+1$ ions give rise to $a_{n}$ and $d_{H}$ ions [28]. The fall in relative intensities of the $a_{7}+1$ and $a_{8}+1$ peaks, together with the formation of $d_{7}$ and $d_{8}$ ions on switching from helium to argon as the target gas, provides clear evidence that the $a_{7}+1$ and $a_{8}+1$ ions are formed with greater internal energies when argon is used as the target gas.

Figures 2-4 show similar pairs of CID spectra for the $\mathrm{MH}^{+}$ions of the peptides [des-Arg ${ }^{9}$ ]-bradykinin, renin substrate, and the CLIP peptide. These peptides all contain an arginine residue at or near their $\mathrm{N}$ terminal end. Together with substance $P$, they cover a mass range of 905-2465 u. As discussed above, the multiplication factors shown in the figures for different regions of the CID spectra reflect the heights of the fragment ion peaks relative to the primary ion and so may be used as a measure of the efficiency of

Table 1. Comparison of the relative abundances of $a_{7}, a_{7}+1$, $\mathrm{d}_{7}, \mathrm{a}_{8}, \mathrm{a}_{8}+1$, and $\mathrm{d}_{8}$ fragment ions in the CID spectrum of the $\mathrm{MH}^{+}$ion of substance $\mathrm{P}$ using helium and argon as collision gases.

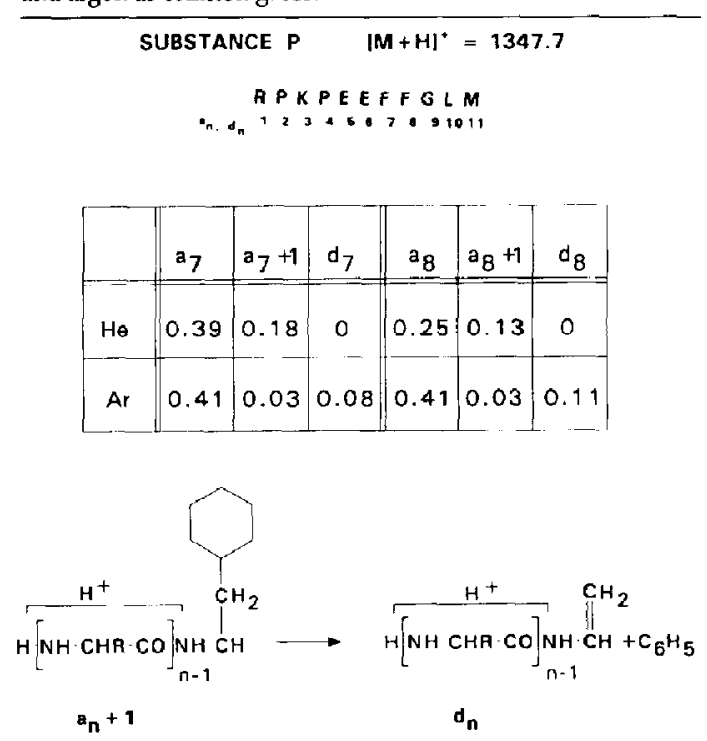

fragment ion production as a function of RMM and target gas. For the two lower mass peptides, [desArg ${ }^{9}$ l-bradykinin and substance $P$ (Figures 1 and 2), the fragment ion peaks in the spectra obtained using helium and argon as target gases are comparable. For the higher mass peptides (Figures 3 and 4), however, the heights of peaks due to fragment ions in the helium CID spectra are much lower than those found in the argon CID spectra. It appears that the efficiency of helium as a target gas for inducing the decomposition of $\mathrm{MH}^{+}$ions of the type of peptides discussed in this section drops dramatically above $\sim 1500 u$, whereas the efficiency of argon is relatively independent of mass over the range 905-2465 $u$.

\section{Peptides Containing Arginine at the C-Terminal End}

The CID spectra of the $\mathrm{MH}^{+}$ion of fibrinopeptide A obtained by using helium and argon as target gases are shown in Figure 5. The striking difference in the spectra is immediately apparent in that in contrast to the spectrum obtained using helium, that obtained using argon contains intense peaks due to $\mathrm{w}_{n}$ and $\mathrm{v}_{n}$ fragment ions arising from side chain fragmentations covering the entire sequence of the peptide. The heights of the peaks arising from $y_{n}$ ions are essentially unchanged, due to the $y_{14}$ ion being somewhat greater when helium was the target gas. Since $y_{n}$ ions are known to be precursors of $v_{t t}$ ions [28], the differences between the two spectra indicate that when argon is used as the target gas to obtain a CID spectrum, greater amounts of internal energy are on average deposited into the $\mathrm{MH}^{+}$ion of fibrinopeptide $\mathrm{A}$ than when helium is used as the target gas.

Similar differences are observed in the corresponding CID spectra given by the $\mathrm{MH}^{+}$ion of the reduced form of $\left[\mathrm{Arg}^{8}\right]$-vasopressin, which has a relatively low RMM of $1086.5 \mathrm{u}$ (Figure 6), and porcine pancreastatin fragment (33-49) (Figure 7), for which $\mathrm{MH}^{+}$has an RMM of 1846.9. The CID spectra given by a number of other peptides that contained an arginine residue at or near the $\mathrm{C}$-terminal end showed similar features.

\section{Peptides Containing No Basic Amino Acids}

The CID spectra of the $\mathrm{MH}^{+}$ion of the (54-65) fragment of the peptide hirudin in which helium and argon were used as the target gases are shown in Figure 8. Each spectrum contains a nearly complete set of peaks arising from $b_{n}$ and $y_{n}$ ions but no peaks due to ions formed by side chain fragmentations. The overall heights of the peaks arising from fragment ions are similar in the two spectra, and it is evident that the CID spectrum of this peptide does not depend strongly on the nature of the target gas. Similar 


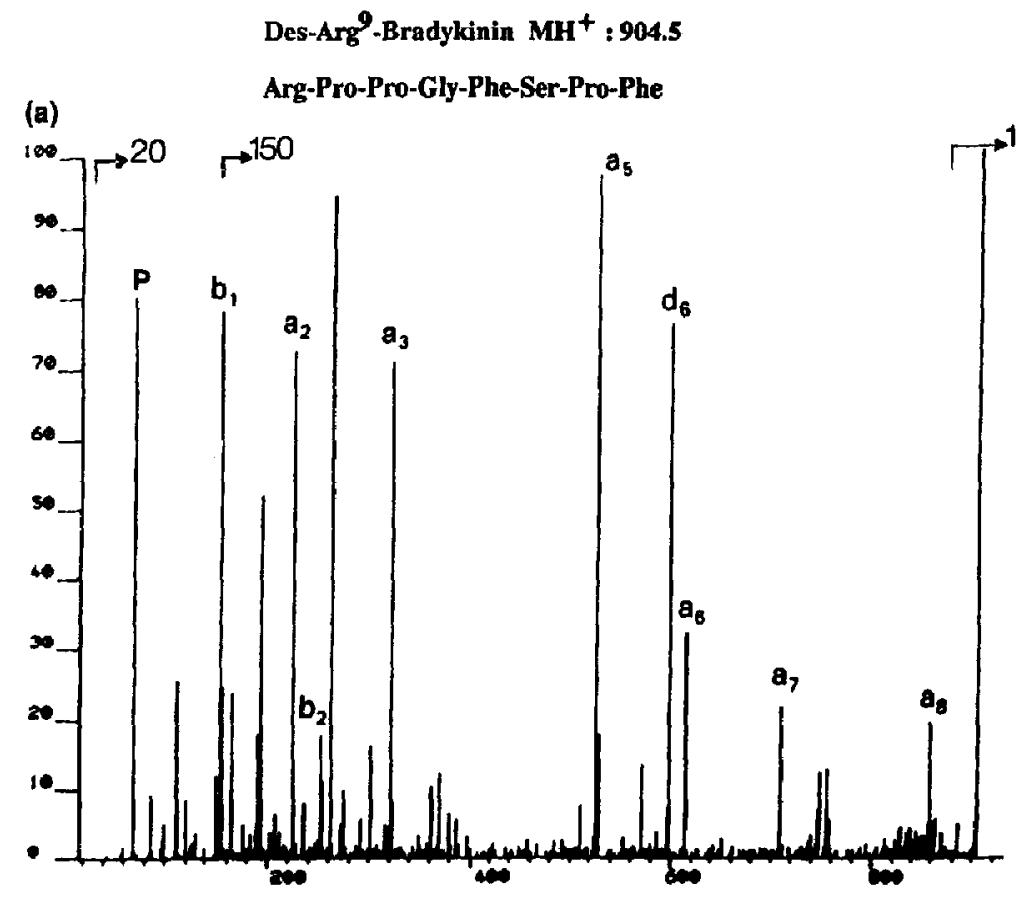

(b)

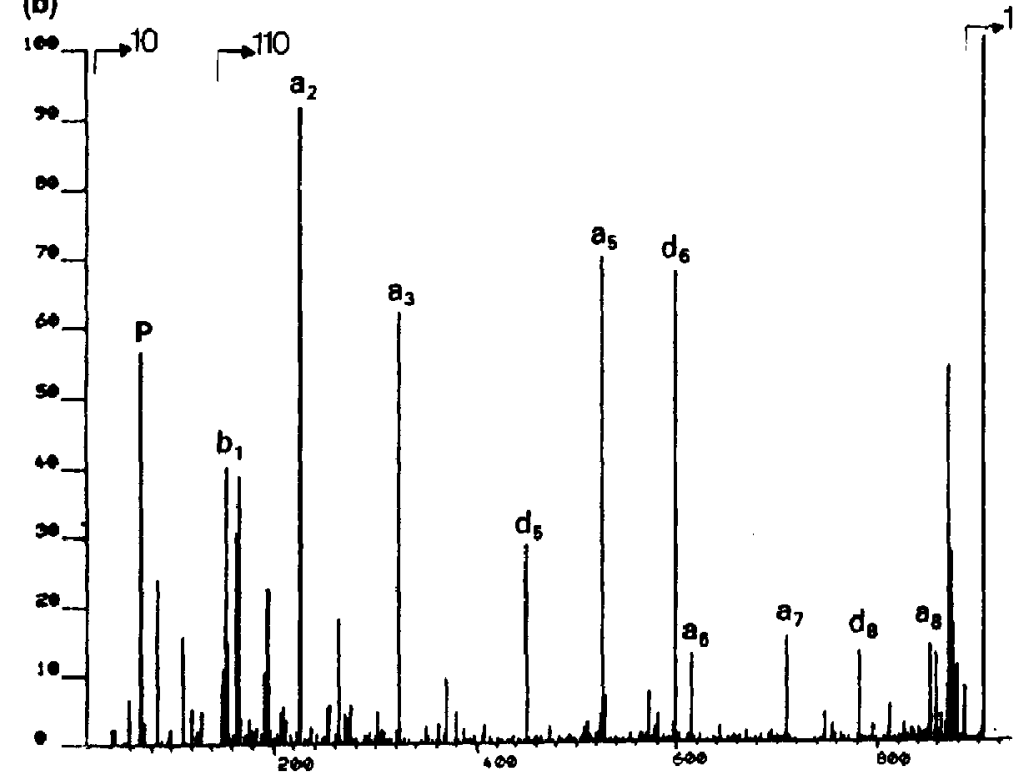

Figure 2. The CID spectrum of the $\mathrm{MH}^{+}$ion of [des-Arg ${ }^{9}$-bradykinin ( $m / z$ 904.5) obtained using (a) helium and (b) argon as the collision gas and a collision cell potential of 4 $\mathrm{kV}$. 


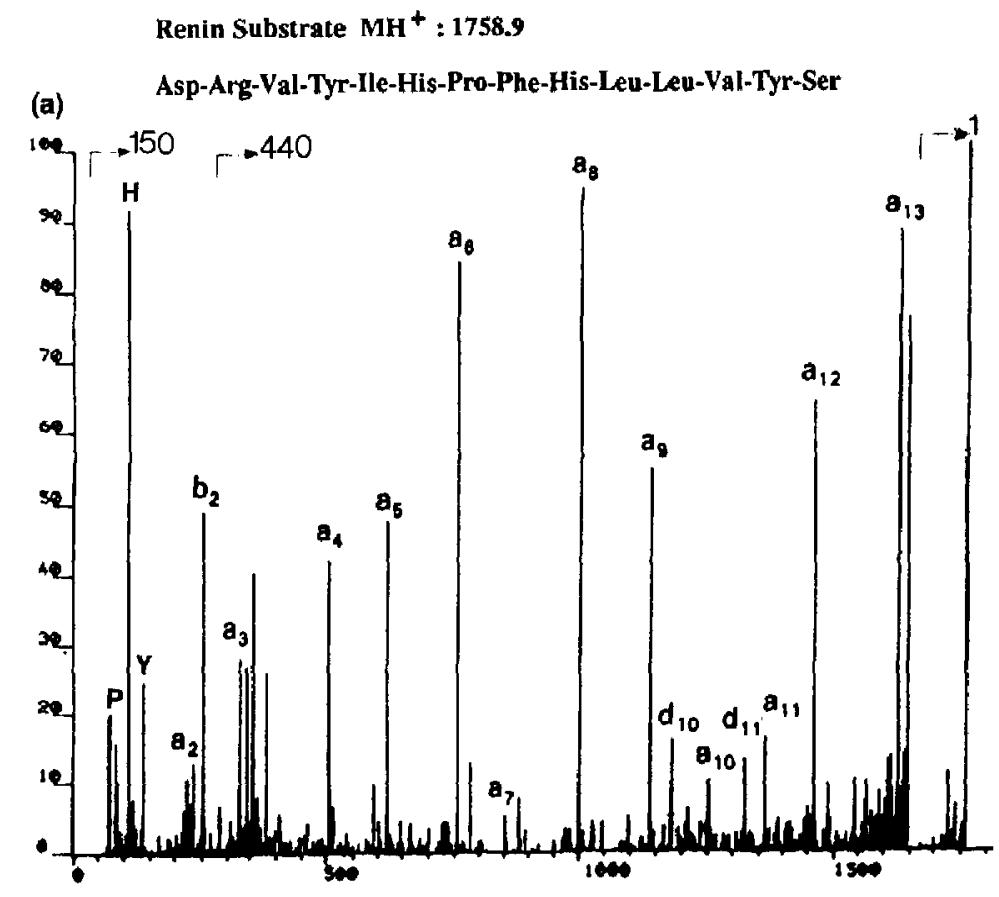

Figure 3. The CID spectrum of the $\mathrm{MH}^{+}$ion of renin substrate $(\mathrm{m} / \mathrm{z}$ 1758.9) obtained using (a) helium and (b) argon as the collision gas and a collision cell potential of $4 \mathrm{kV}$.

(b)

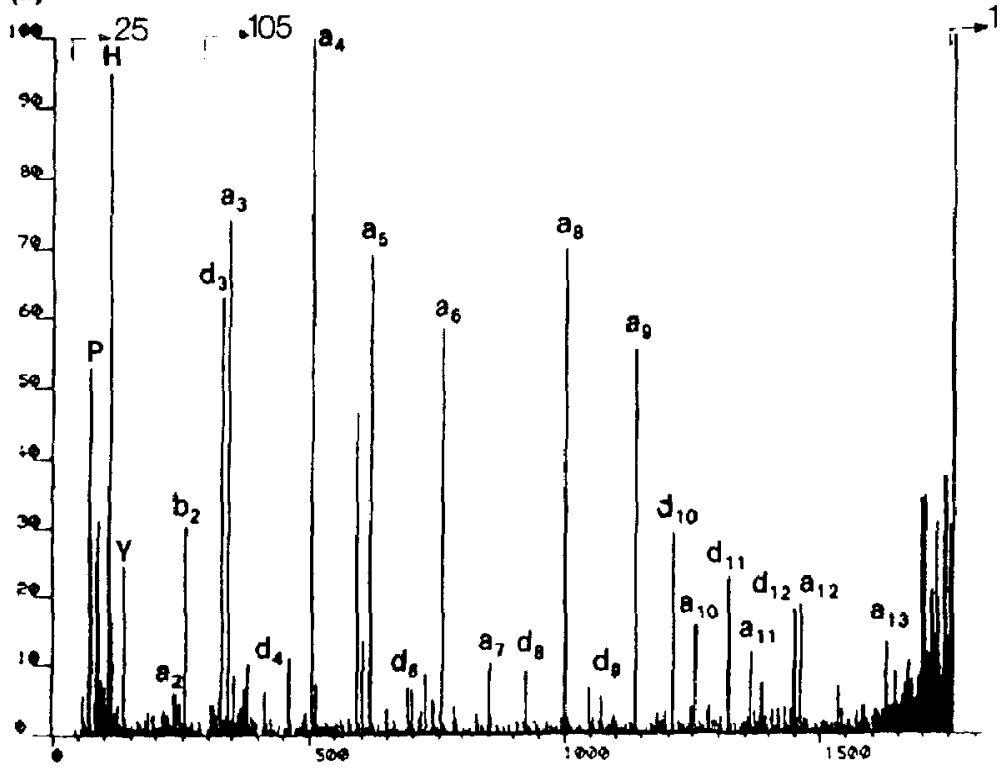


CLIP $\mathrm{MH}^{+}, 2465.2$

Arg-Pro-Val-Lys-Val-Tyr-Pro-Asn-Gly-Ala-Glu-Asp-Glu-Ser-Ala-Glu-Ala-Phe-Pro-Leu-Glu-Phe

(a)

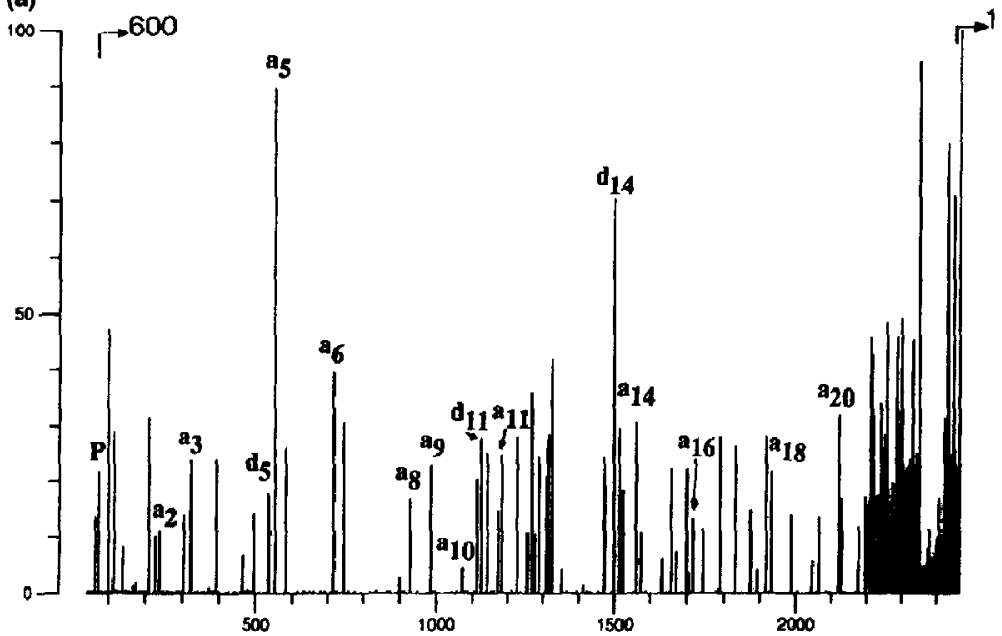

(b)

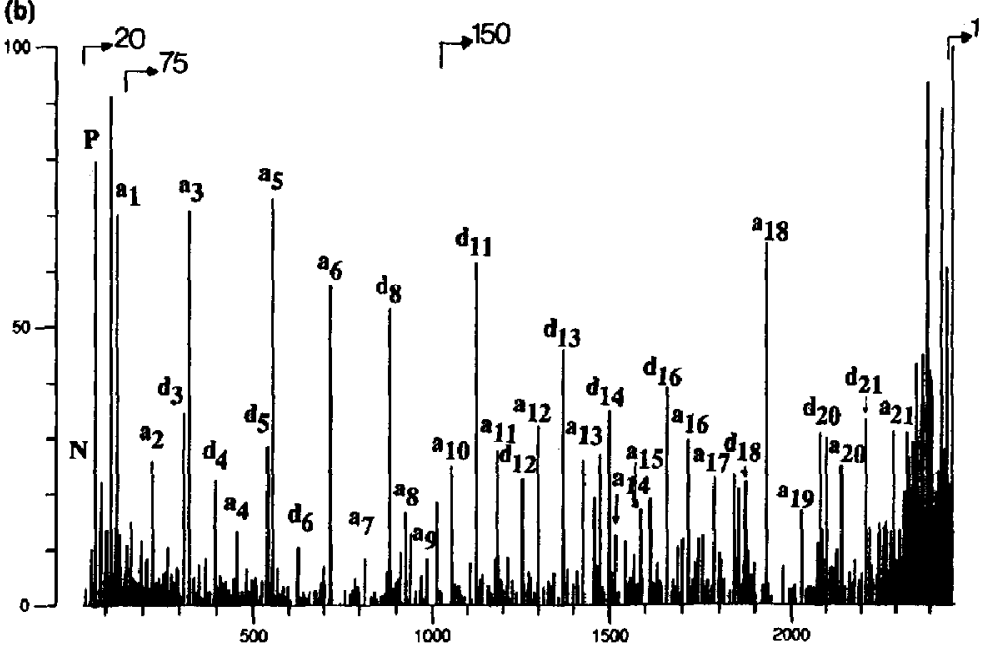

Figure 4. The CID spectrum of the $\mathrm{MH}^{+}$ion of CLIP $(m / z 2465.2)$ obtained using (a) helium and (b) argon as the collision gas and $a$ collision cell potential of $4 \mathrm{kV}$. results were obtained for other peptides that contain no amino acid residues, but as the RMM of the peptide increases, the efficiency of helium as a target gas to promote CID gradually decreases.

\section{Conclusions}

The results indicate that the CID spectra of the $\mathrm{MH}^{+}$ ions of peptides are affected by the nature of the target gas to varying degrees. Peptides that contain a basic amino acid residue, such as arginine, at the C-terminal end show the most marked differences both in the qualitative features of the spectrum and in the overall efficiency of fragmentation when the target gas is switched from helium to argon. If the basic amino acid residue is at the $\mathrm{N}$-terminal end, the difference is less marked but nevertheless quite significant; when helium is used as the target gas, no peaks due to $d_{n}$ ions arising from the fragmentation of amino acid residues having aromatic side chains are observed, and the efficiency of fragmentation relative to that obtained with argon as the target gas falls rapidly above an $\mathrm{RMM}$ of $1500 \mathrm{u}$. If no basic amino acid residue is present in the peptide, the CID spectrum is much less dependent on the nature of the target gas, but the difference in fragmentation efficiencies above an RMM of about $\mathbf{1 5 0 0}$ is still observed.

The results show that in the high energy CID of 
Fibrinopeptide A $\mathrm{MH}^{+}$: 1536.7

Ala-Asp-Ser-Gly-Glu-Gly-Asp-Phe-Leu-Ala-Glu-Gly-Gly-Gly-Val-Arg

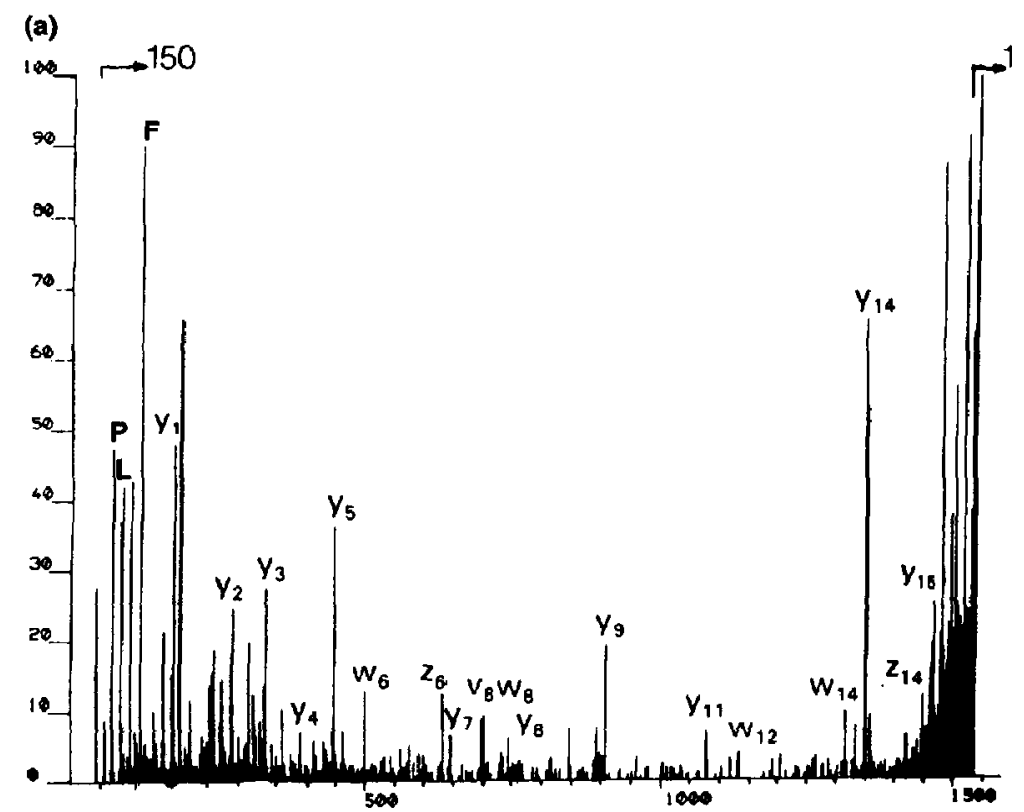

(b)

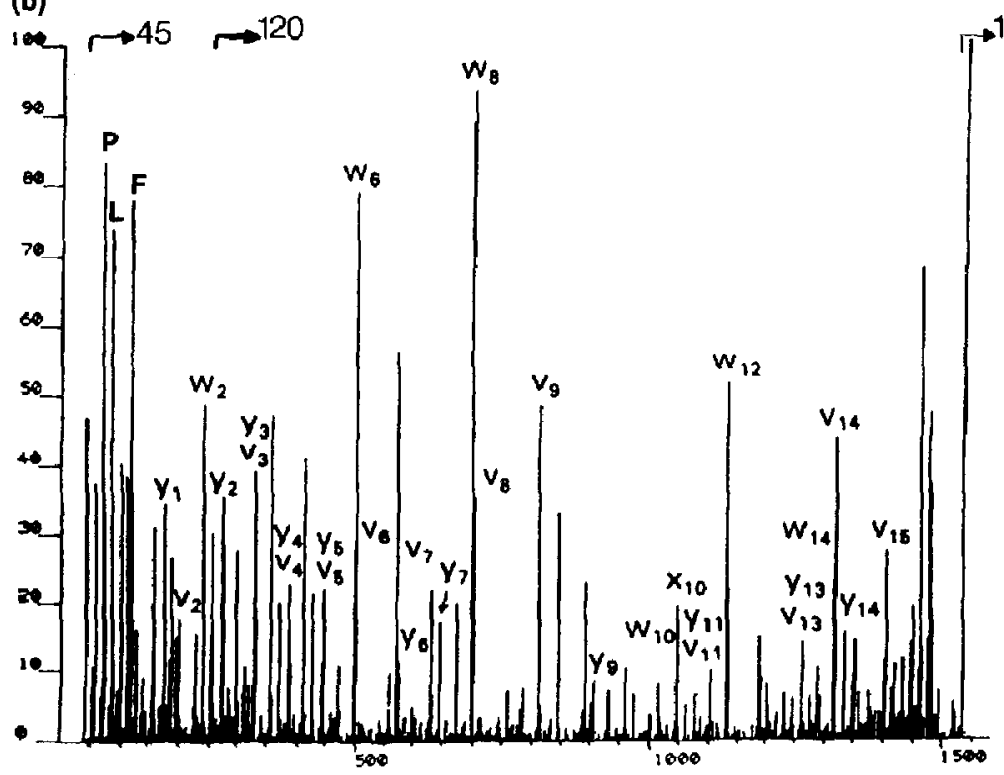

Figure 5. The CID spectrum of the $\mathrm{MH}^{+}$ion of fibrinopeptide A $(\mathrm{m} / \mathrm{z}$ 1536.7) obtained using (a) helium and (b) argon as collision gas and a collision cell potential of $4 \mathrm{kV}$. 
[Arg $\left.{ }^{8}\right]$-Vasopressin $\mathrm{MH}^{+}: 1086.5$

(a)

Cys-Tyr-Phe-GIn-Asn-Cys-Pro-Arg-Gly-NH2

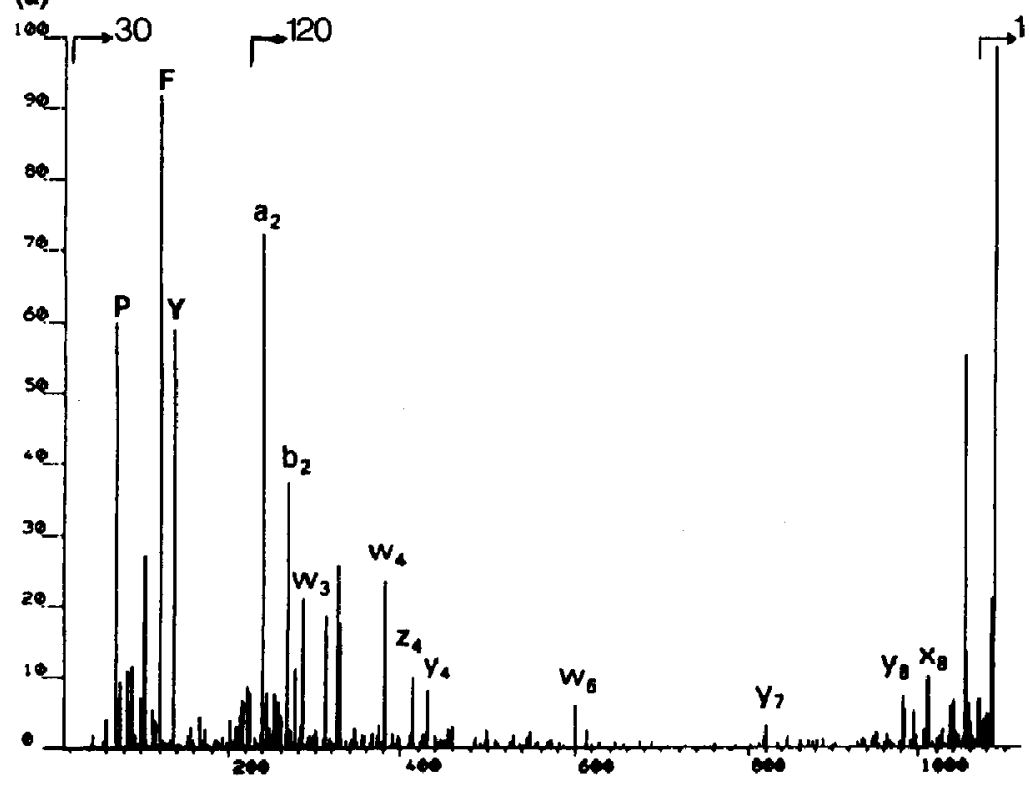

(b)

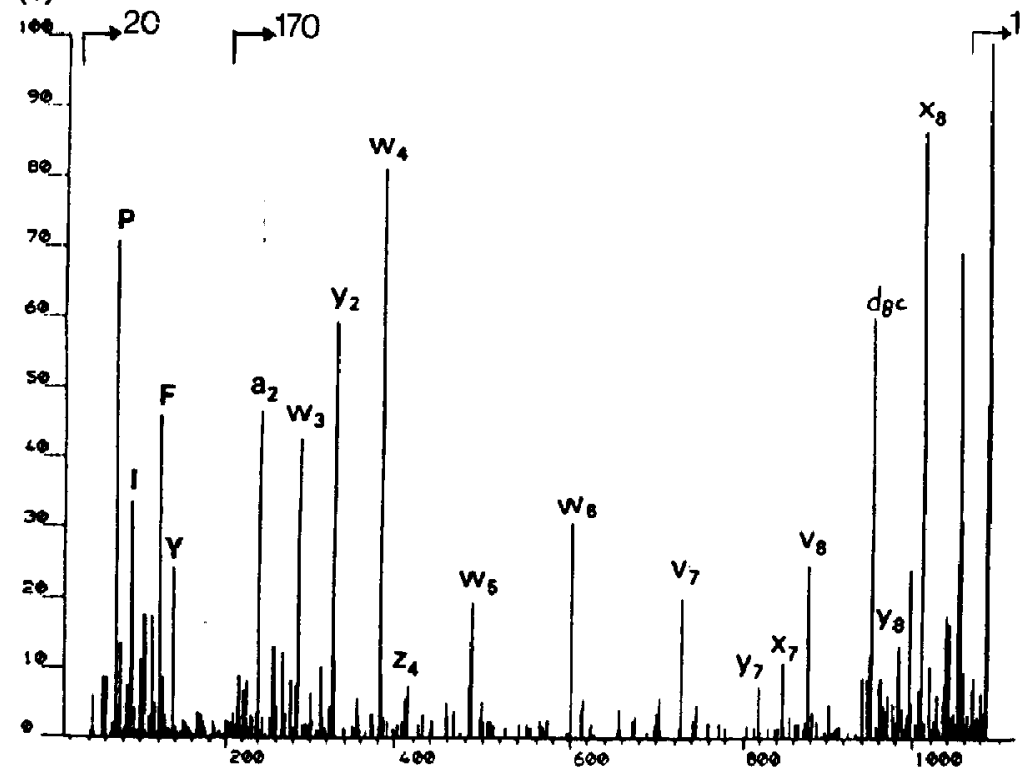

Figure 6. The CID spectrum of the $\mathrm{MH}^{+}$ion of $\left[\mathrm{Arg}^{8}\right]$-vasopressin ( $m / z$ 1086.5) obtained using (a) helium and (b) argon as collision gas and a collision cell potential of $4 \mathrm{kV}$. 
Porcine pancreastatin fragment [33-49] $\mathrm{MH}^{+}: 1846.9$

Gln-GIu-GIu-GIu-Glu-Glu-Thr-Ala-Gly-Ala-Pro-GIn-Gly-Leu-Phe-Arg-Gly-NH2
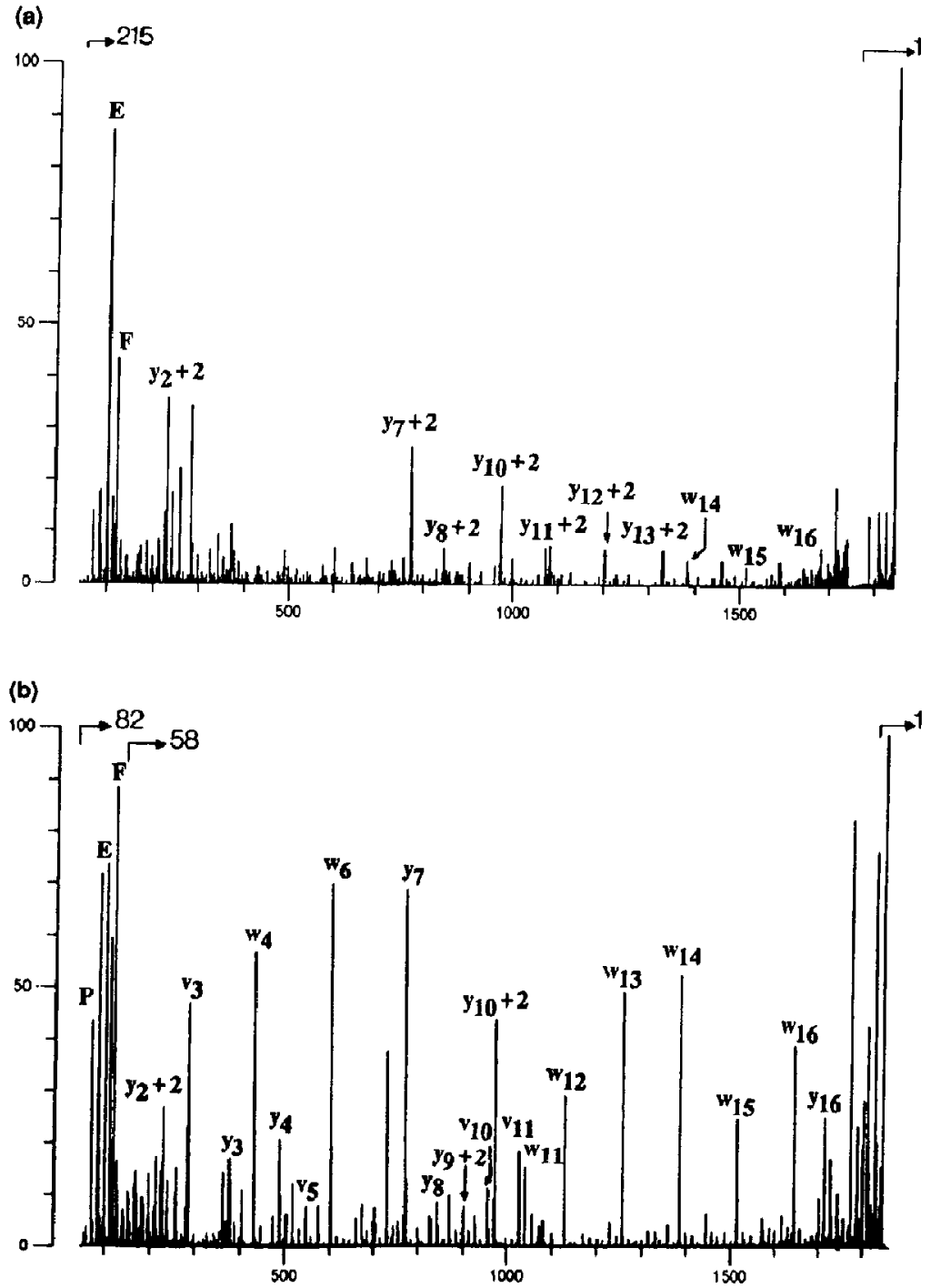

Figure 7. The CID spectrum of the $\mathrm{MH}^{+}$ion of porcine pancreastatin $(m / z$ 1846.9) obtained using (a) helium and (b) argon as the collision gas and a collision cell potential of 4 $\mathrm{kV}$. peptides of RMM above about $1000 \mathrm{u}$, the use of the heavier target gas, argon, leads to the deposition on average of larger amounts of internal energy than when helium is the target gas. This conclusion is the reverse of that reached by a number of authors [35-38] based on observations of the high energy CID of smaller polyatomic ions. It has been shown [36, 37] that for polyatomic ions of RMM below about $300 \mathrm{u}$, high energy collisions with helium rather than argon result in the generation of more abundant fragments and more fragments formed in high energy fragmen- tation processes. These observations are explained by assuming that in high energy collisions, the most important excitation is electronic excitation $[35,38]$, for which helium has a large cross section (see ref 39 for a review of collisional excitation mechanisms). The results reported here indicate that above an RMM of about $1000 \mathrm{u}$, electronic excitation is neither the only nor the most important excitation mechanism in high energy collisions. Vibrational excitation, brought about by any of the several possible mechanisms previously suggested [39], is consistent with the observed depen- 


\section{Hirudin fragment [54-65] $\mathrm{MH}^{+}: \mathbf{1 4 6 8 . 6}$}

\section{Gly-Asp-Phe-GIu-Glu-Ile-Pro-Glu-Glu-Tyr-Leu-Gln}

(a)

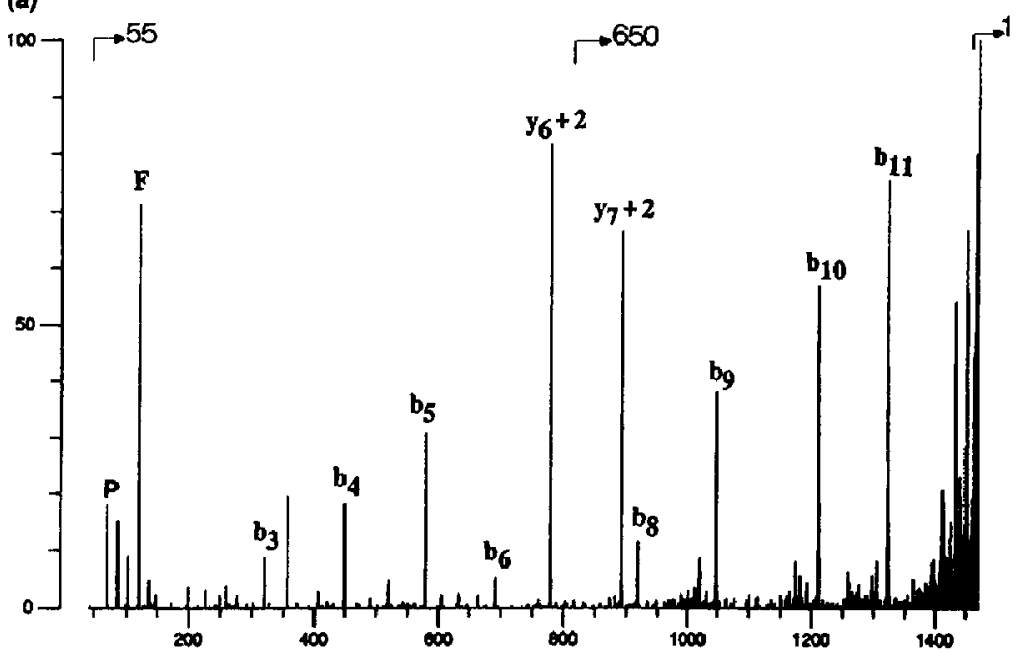

(b)

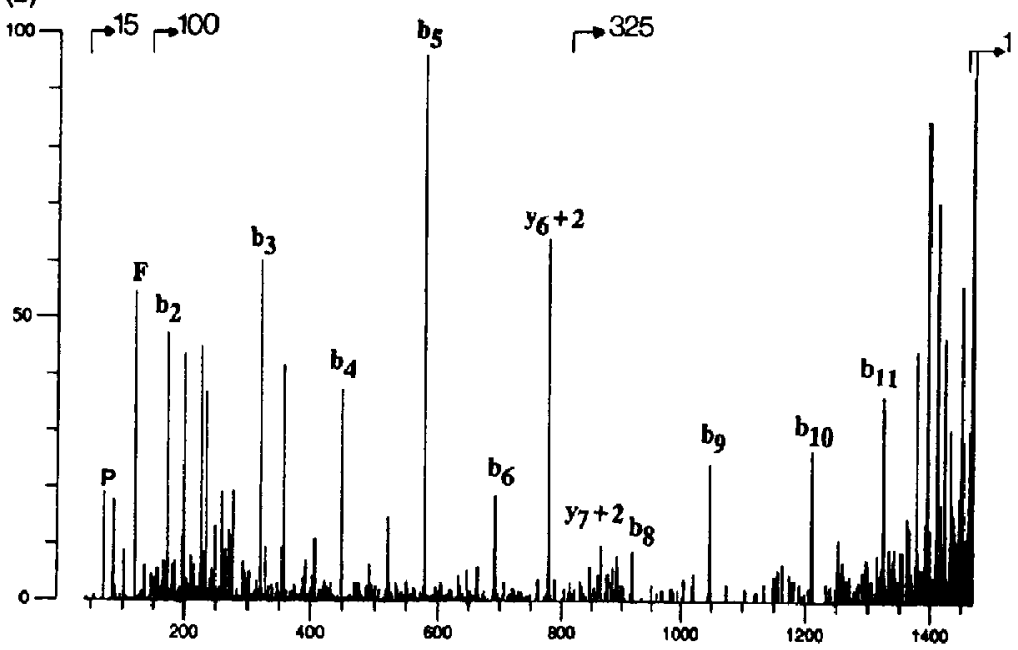

Figure 8. The CID spectrum of the $\mathrm{MH}^{+}$ion of hirudin fragment (54-65) ( $m / z$ 1468.6) obtained using (a) helium and (b) argon as the collision gas and a collision cell potential of $4 \mathrm{kV}$.

dence of the CID spectra on the mass of the target gas.

\section{Acknowledgments}

We thank SERC, ICI plc, and Shell Research for financial support during the course of this work.

\section{References}

1. Barber, M.; Bordoli, R. S.; Sedgwick, R. D.; Tyler, A. N. J. Chem. Soc. Commun. 1981, 325.

2. Aberth, W.; Straub, K. M.; Burlingame, A. L. Anal. Chem. 1982, 52, 2029.

3. McLafferty, F. W. Tandem Mass Spectrometry; Wiley: New York, 1983.
4. Hunt, D. F.; Bone, W. M.; Shabanowitz, J.; Rhodes, J.; Ballard, J. M. Anal. Chem. 1981, 53, 1704.

5. Hunt, D. F.; Yates III, J. R.; Shabanowitz, J.; Winston, S.; Hauer, C. R. Proc. Natl. Acad. Sci. USA 1986, 83, 6233.

6. Gaskell, S. J.; Reilly, M. H.; Porter, C. J. Rapid Commun. Mass Spectrom. 1988, 2, 142.

7. Reilly, M. H.; Gaskell, S. J. Proceedings of the 36th Annual ASMS Conference on Mass Spectrometry and Allied Topics, San Francisco, 1988, p 137.

8. Alexander, A. J.; Boyd, A. J. Int. J. Mass Spectrom. Ion Proc. 1989, 90, 211.

9. Alexander, A. J.; Thibault, P.; Boyd, A. J. Rapid Commun. Mass Spectrom. 1989, 3, 30.

10. Alexander, A. J.; Thibault, P.; Boyd, A. J.; Curtis, J. M.; Rinehart, K. L. Int. J. Mass Spectrom. Ion Proc. 1990, 98, 107. 
11. Bean, M. F.; Carr, S. A.; Thorne, G. C.; Reilly, M. H.; Gaskell, S. J. Anal. Chem. 1991, 63, 1473.

12. Grnss, M. I.; Tomer, K. B.; Cerny, R. L.; Giblin, D. E. In: Mass Spectrometry in the Analysis of Large Molecules; McNeal, C. J., Ed.; Wiley: New York, 1986, pp 171-190.

13. Bruins, A. P.; Jennings, K. R.; Evans, S. Int. J. Mass Spectrom. Ion Proc. 1978, 26, 395.

14. Hass, J. R.; Green, B. N.; Bateman, R. H.; Bott, P. A Proceedings of the 32nd Annual ASMS Conference on Mass Spectrometry and Allied Topics, San Antonio, 1984, p 380.

15. Sato, K.; Asada, T.; Ishihira, M.; Kunihuro, F.; Kammai, Y.; Kubota, E.; Costello, C. E.; Martin, S. A.; Scoble, H. A.; Biemann, K. Anal. Chem. 1987, 59, 1652.

16. Carr, S. A.; Green, B. N.; Hemling, M. E.; Roberts, C. D.; Anderegg, R. J.; Vickers, R. Proceedings of the 35th Annual ASMS Conference on Mass Spectrometry and Allied Topics, Denver, 1987, p 830.

17. Ashcroft, A. E.; Buchanan, R. A. C.; Elliot, G. J.; Evans, S.; Milton, D. J.; Wright, B. Proceedings of the 36 th Annual ASMS Conference on Mass Spectrometry and Allied Topics, San Francisco, 1988, p 1156

18. Biemann, K.; Scoble, H. A. Science 1987, 237, 992.

19. Curtis, J. M.; Rong, L. S.; Milberg, R. M.; Rinehart, K. L. Proceedings of the 36 th Annual ASMS Conference on Mass Spectrometry and Allied Topics. San Francisco, 1988, p 147.

20. Despeyroux, D.; Bordas-Nagy, J.; Jennings, K. R. Rapid Commun. Mass Spectrom. 1991, 4, 156.

21. Roepstorff, P.; Fohlman, J. Biomed. Mass Spectrom. 1984, 11, 601 .

22. Biemann, K. Biomed. Environ. Mass Spectrom. 1988, 16, 99.

23. Barber, M.; Bordoli, R. S.; Sedgwick, R. D.; Tyler, A. N.; Whalley, E. T. Biomed. Mass Spectrom. 1981, 8, 337.

24. Williams, D. H.; Bradley, C. V.; Santikarn, S.; Bojesen, G. Biochem. J. 1982, 201, 105.

25. Morris, H. M.; Panico, M.; Barber, M.; Bordoli, R. S.;
Sedgwick, R. D.; Tyler, A. N. Biochem. Biophys. Res. Commun. 1981, 101, 623.

26. Martin, S. A.; Biemann, K. Int. I. Mass Spectrom. Ion Proc. 1987, 78, 213.

27. Johnson, R. S.; Martin, S. A.; Biemann, K.; Stults, J. T.; Throck Watson, J. Anal. Chem. 1987, 59, 2631.

28. Johnson, R. S.; Martin, S. A.; Biemann, K. lnt. J. Mass Spectrom. Ion Proc. 1988, 86, 137.

29. Martin, S. A.; Johnson, R. S.; Costello, C. E.; Biemann, K. In: The Analysis of Peptides and Proteins by Mass Spectrometry; McNeal, C. J., Ed.; Wiley: New York, 1988, pp 135-150.

30. Martin, S. A. Proceedings of the 37th Anmual ASMS Conference on Mass Spectrometry and Allied Topics, Miami, 1989, p 858.

31. Johnson, R. S.; Martin, S. A.; Vath, J. E.; Biemann, K. Proceedings of the 36th Annual ASMS Conference on Mass Spectrometry and Allied Topics, San Francisco, 1988, p 1148.

32. Biemann, K. In: Methods in Enzymology, ool. 193: Mass Spectrometry; McCloskey, J. A., Ed.; Academic Press, San Diego, 1990; pp 455-480.

33. Poulter, L.; Taylor, L. C. Int. J. Mass Spectrom. Ion Proc. 1989, 91, 183.

34. Jensen, N. J.; Tomer, K. B.; Gross, M. L. I. Am. Chem. Soc. 1985, 107, 1863

35. Kim, M. S.; McLafferty, F. W. I. Am. Chem. Soc. 1978, 100, 3279 .

36. Laremee, J. A.; Cameron, P.; Cooks, R. G. J. Am. Chem. Soc. 1981, 103, 12.

37. Ouwerkerk, C. E. D.; McLuckey, S. A.; Kistemaker, P. G.; Boerbom, A. J. H. Int. ]. Mass Spectrom. Ion Proc. 1984, 56, 11.

38. Kẹnttämaa, H, 1.; Cooks, R, G. Int. I. Mass Spectrom. Ion Proc. 1987, 75, 181.

39. Bordas-Nagy, J.; Jennings, K. R. Int. J. Mass Spectrom. Ion Proc. 1990, 100, 105. 